\title{
OS TRÊS MOMENTOS PEDAGÓGICOS COMO ESTRUTURANTES DE CURRÍCULOS: O ESTUDO DA REALIDADE E OS TEMAS GERADORES NA EDUCAÇÃO EM CIÊNCIAS
}

\author{
THE THREE PEDAGOGICAL MOMENTS AS CURRICULUM STRUCTURERS: THE STUDY OF REALITY AND GENETIC \\ THEMES IN SCIENCE EDUCATION
}

TRES VECES MÁS PLANES DE ESTUDIO DE LA TRANSFORMACIÓN ESTRUCTURAL: LA REALIDAD DE LOS

ESTUDIOS Y GENERADORES TEMAS EN CIENCIAS DE LA EDUCACIÓN

\author{
PANIZ, Catiane Mazoco 1 \\ CENTA, Fernanda Gall2 \\ ARAÚJO, Laís Baldissarelli3 \\ MUENCHEN, Cristiane 4
}

\section{RESUMO}

Ainda hoje é possível reconhecer um ensino de ciências descontextualizado e fragmentado, tornando o processo de ensino e aprendizagem, muitas vezes, desconexo da realidade vivenciada pelos educandos. Nesse sentido, o presente trabalho tem por objetivo apresentar resultados obtidos a partir de três processos formativos que abrangeram seis escolas públicas, envolvendo professores de Biologia, Química e Física no Estudo da Realidade para chegar aos Temas Geradores a partir da utilização dos Três Momentos Pedagógicos (3MP) como estruturantes de currículos. Destaca-se a importância de considerar a realidade na elaboração de currículos mais reflexivos e críticos, bem como a interação entre formação inicial e continuada na busca de uma escola mais alegre e que proporcione a construção de conhecimentos.

Palavras-chave: Temas Geradores. Três Momentos Pedagógicos. Ensino de Ciências e Formação de Professores.

\section{ABSTRACT}

Even today it is possible to recognize a decontextualized and fragmented science education, making the process of teaching and learning often disconnected from the reality experienced by the students. In this sense, the present work aims to present results obtained from three training processes that included six public schools, involving teachers of Biology, Chemistry and Physics in the Study of Reality to reach the Generating Themes from the use of the Three Pedagogical Moments (3MP) as curriculum structuring. The importance of considering reality in the elaboration of more reflexive and critical curricula, as well as the interaction between initial and continued formation in the search for a more cheerful school and that provides the construction of knowledge.

Keywords: Generator Themes. Three Pedagogical Moments. Teaching Science and Teacher Training.

\section{RESUMEN}

Todavía es posible reconocer una enseñanza de las ciencias descontextualizado y fragmentado, haciendo que el proceso de enseñanza y aprendizaje, a menudo desconectado de la realidad experimentada por los estudiantes. En este sentido, el presente trabajo tiene como objetivo presentar los resultados a partir de tres procesos formativos que abarcan seis escuelas públicas, la participación de los profesores de biología, química y física en el Estudio de la Realidad para llegar Temas generadores de la utilización de los tres momentos pedagógicos (3MP) como los planes de estudio de estructuración. Se destaca la importancia de considerar la realidad en el desarrollo de los programas más reflexivos y críticos, así como la interacción entre la educación inicial y continua en la búsqueda de una escuela deportiva y proporciona la construcción del conocimiento.

Palabras clave: Temas Generadores. Tres momentos pedagógicos. Ciencias de la Educación y la formación del professorado.

\footnotetext{
1 Instituto Federal de Farroupilha - IFF - Farroupilha - Rio Grande do Sul - Brasil.

2 Universidade Federal de Santa Maria - UFSM - Santa Maria- Rio Grande do Sul - Brasil.

${ }^{3}$ Universidade Federal de Santa Maria - UFSM - Santa Maria- Rio Grande do Sul - Brasil.

${ }^{4}$ Universidade Federal de Santa Maria - UFSM - Santa Maria- Rio Grande do Sul - Brasil.
} 


\section{INTRODUÇÃO}

O ensino de ciências, ainda hoje, é baseado na transmissão de informações, não possibilitando, muitas vezes, a discussão e reflexão sobre o currículo. Este, muitas vezes, é visto como uma listagem de conteúdos a serem seguidos e trabalhado de maneira disciplinar, fragmentada e descontextualizada, e estão associados ao que Freire (2013) denominou de "educação bancária". Essa visão de currículo já vem sendo problematizada por alguns autores como (AULER, 2007; DELIZOICOV; ANGOTTI, PERNAMBUCO, 2011; HALMENSCHLAGER, 2014), e também por documentos oficiais, como as Diretrizes Curriculares Nacionais para Educação Básica (2013) e o Pacto Nacional pelo Fortalecimento do Ensino Médio (2013).

De acordo com Maldaner (2007) o cenário atual dos currículos das ciências é resultado de um processo histórico no qual organiza e elabora suas ações pensando na preparação para o ensino superior. Dessa forma, o que se leva em consideração são os conteúdos necessários para a aprovação e ingresso nas instituições de ensino superior.

Nesse contexto, uma das possibilidades que vem sendo discutida é a utilização da Abordagem Temática Freireana (ATF) para pensar, elaborar e implementar currículos contextualizados e interdisciplinares. Nesta perspectiva, os temas geradores possuem foco central, sendo que os conteúdos a serem trabalhados derivam ou atendem as necessidades desses. O tema gerador, por sua vez, deve propiciar significado aos educandos e, por isso, está atrelado às demandas sociais, culturais e econômicas da localidade desses (CENTA, 2015).

Tais propostas encontram-se associadas a concepções progressistas de educação, as quais colocam em prioridade no debate educacional a elaboração de propostas pedagógicas que almejam a construção da cidadania e o exercício de princípios de justiça social aspirando à transformação da sociedade. Essas concepções, quando apoiadas nos pressupostos freireanos, consideram a prática didática da educação problematizadora e dialógica como uma exigência metodológica e presumem a expressão dos homens perante o mundo (FREIRE, 2013). Consideram, ainda, a prática como uma ação reflexiva e premeditada, visando transformar a maneira de agir.

Para ocorrer tais propostas e possibilidades de mudanças, devem-se colocar os conflitos da realidade local e da sociedade como alicerce estruturante da programação curricular. Nesse sentido, destacam-se os Três Momentos Pedagógicos (3MP) como estruturantes de currículos (MUENCHEN, 2010), onde os temas geradores emergem do Estudo da Realidade local, etapa em que se levantam situações significativas da comunidade e realidade escolar.

Contudo, desenvolver práticas a partir da ATF torna-se um grande desafio, principalmente pelo fato de estar dissociada das práticas cotidianas dos professores. Nesse sentido, a formação de professores tem papel importante, pois é imprescindível que os professores não se vejam mais como reprodutores de currículos mas também como sujeitos que pensam e elaboram currículos a partir da realidade vivenciada. 
Em função disso, defende-se que a participação dos professores na elaboração de currículos para a Educação Básica é um importante espaço de formação. Espera-se, por meio de cursos de formação permanente, que os professores venham a tomar conhecimento dessas propostas educativas capazes de apontar pressupostos para a escolha de critérios que permitam articular o mundo da escola com o mundo da vida, e ainda, que possam planejar seus conteúdos estabelecendo essas relações e, com isso, repensem suas práticas pedagógicas e curriculares (CENTA; MUENCHEN, 2015). presente trabalho, portanto, procura discutir reestruturações curriculares fundamentadas na perspectiva da ATF, com foco nos 3MP como estruturantes de currículos.

\title{
Os Três Momentos Pedagógicos como Estruturantes de Currículos
}

Segundo Muenchen e Delizoicov (2012), a dinâmica conhecida como 3MP, passou a se disseminar no final da década de 80, especialmente pela distribuição dos livros "Metodologia do Ensino de Ciências" (DELIZOICOV; ANGOTTI, 1992) e "Física" (DELIZOICOV; ANGOTTI, 1990) nas escolas públicas de nível médio do Brasil, por meio de um programa do INEP/MEC.

Além disso, de acordo com os autores, esses materiais passaram a constar nas referências bibliográficas de cursos de licenciatura da área de Ciências, de programas de pós-graduação, em concursos públicos para a carreira de magistério e cursos de formação continuada de docentes.

Na perspectiva dos autores dos 3MP, ou seja, de uma abordagem temática, os conceitos deixam de ter um fim em si, passando a constituir-se em meios, ferramentas para compreensão de algo mais amplo, isto é, dos temas socialmente relevantes (MUENCHEN, 2010, p.109).

Os 3MP como estruturantes de currículos fizeram parte de tentativas de reestruturação de currículos, como por exemplo, em 1989, quando Paulo Freire assumiu a Secretaria Municipal de Educação no município de São Paulo. Neste mandato, foi apresentado por Freire um projeto rumo à construção de uma escola pública, popular, democrática e de qualidade pautada em quatro principais objetivos, sendo eles:

\begin{abstract}
Ampliar o acesso e a permanência dos setores populares - virtuais únicos usuários da educação pública; Democratizar a gestão, o poder pedagógico e educativo para que todos, alunos, funcionários, professores, técnicos educativos, pais de família se vinculem num planejamento autogestionado, aceitando as tensões e contradições sempre presentes em todo esforço participativo, porém buscando uma substantividade democrática; Incrementar a qualidade da educação, mediante a construção coletiva de um currículo interdisciplinar e a formação permanente do pessoal docente; Eliminar o analfabetismo de jovens e adultos em São Paulo (FREIRE, 2001, p. 14-15).
\end{abstract}

Este foi chamado de Projeto Interdisciplinar do município de São Paulo, também chamado de Projeto Interdisciplinar via Tema Gerador ou Projeto Inter (MUENCHEN, 2010, p. 119).

Segundo Centa (2015), também, discutiram-se, nesse projeto, fundamentos da proposta pedagógica da escola pela via da interdisciplinaridade e os pontos principais da proposta: o trabalho coletivo, as posturas, os temas geradores, a formação dos educadores, a metodologia e o programa. E, 
por fim, foram propostos alguns encaminhamentos para a ação pedagógica na escola pela via interdisciplinar através do estudo preliminar da localidade, da escolha dos temas geradores e da construção e desenvolvimento do programa por cada escola envolvida.

Como estruturantes de currículos, os momentos pedagógicos são desenvolvidos a partir da Investigação Temática e Redução Temática (FREIRE, 2013) e são conhecidos como: Estudo da Realidade (ER), Organização do Conhecimento (OC) e Aplicação do Conhecimento (AC).

Estudo da Realidade (ER): este momento destina-se a obtenção de informações sobre a comunidade na qual está inserida a escola. Esta investigação ocorre a partir de um dossiê que contém entrevistas, questionários, conversas informais, análises de documentos, entre outros. São investigados também os interesses e expectativas da comunidade escolar. Neste primeiro momento, determinam-se as situações significativas da comunidade e escola investigada. Essa etapa tem como objetivo chegar à concepção individual e coletiva dos problemas que a comunidade enfrenta, pois revelam práticas sociais, suas intenções, valores políticos e éticos, concepções que, ao serem problematizadas de forma contextualizada, podem revelar limites na percepção de contradições sociais (MUENCHEN, 2010).

O ER tem como objetivo a participação de toda a comunidade escolar na coleta das informações da comunidade local, possibilitando que os docentes tornem-se investigadores da realidade que os educandos estão inseridos, viabilizando, com isso, uma troca de informações entre comunidade escolar e comunidade local. Ainda, a troca de conhecimentos entre comunidade e escola resulta do diálogo construído pelo ER, o qual valoriza a experiência existencial denominada por Paulo Freire, sendo esta o ponto de partir para a construção conjunta dos conhecimentos necessários para que seja possível a formação de cidadãos ativos na sociedade em que estão inseridos, possibilitando com isso, que estes sejam capazes de compreenderem, modificarem e tomarem decisões na sociedade.

Organização do Conhecimento (OC): Neste momento, utilizam-se os dados emergidos no primeiro momento, ou seja, no ER, para que sejam definidos pelo coletivo de professores quais serão as questões geradoras e os conteúdos específicos que deverão ser trabalhados para a compreensão do tema gerador. Este momento destina-se aos planejamentos por áreas (MUENCHEN, 2010; MUENCHEN, DELIZOICOV, 2012).

A OC tem por finalidade a inter-relação entre os temas e as situações verificadas que são vivenciadas pela comunidade com os conteúdos a serem trabalhados, buscando, com isso, a compreensão da realidade.

Neste momento, compreende-se que as informações coletadas no ER são trabalhadas e discutidas pelas disciplinas, possibilitando com isso, uma compreensão do tema emergido deste processo, potencializando aos educandos uma compreensão crítica não só da realidade que o cerca, mas também de um cenário que engloba situações macro sociais. 
Por fim, a última etapa da organização curricular baseada pelos 3MP, é conhecida como Aplicação do Conhecimento (AC). Este momento destina-se à implementação das atividades em sala de aula e à avaliação do programa, avaliação caracterizada também pela "planificação de atividades que demonstrem as construções de conhecimento" (TORRES, O'CADIZ, WONG, 2002, p. 148).

Araújo (2015) destaca, em sua dissertação de mestrado, que por se tratar de uma perspectiva dialógica e problematizadora que estrutura os momentos pedagógicos, não é possível restringir a avaliação como sendo classificatória, a qual visa apenas ao produto final. Nesta perspectiva dos 3MP, a avaliação está inserida em todas as etapas do desenvolvimento curricular.

No presente artigo, com foco em práticas formativas vivenciadas na Educação em Ciências, na região central do RS, busca-se refletir sobre como chegou-se aos temas geradores utilizando a dinâmica dos 3MP.

\section{METODOLOGIA}

Partindo da ideia que a utilização dos 3MP como estruturantes de currículos pode contribuir na construção de currículos de ciências mais contextualizados e problematizadores, apresenta-se o trabalho desenvolvido em duas dissertações de mestrado e uma tese de doutorado em andamento, totalizando seis escolas/comunidades investigadas. (ARAÚJO, 2015; CENTA 2015; PANIZ, 2015).

Nos três trabalhos foram discutidos como se chegou ao tema gerador, como aconteceu o desenvolvimento do processo formativo coletivo e interdisciplinar com os educadores com vistas à construção/reconstrução do currículo, através da utilização da ATF, como aconteceu a elaboração e implementação dos materiais confeccionados pelos educadores sobre o tema gerador que emergiu em cada escola, bem como seus resultados.

No entanto, no presente estudo, o objetivo é apresentar e refletir sobre a busca e obtenção do tema gerador a partir do ER.

Anteriormente ao ER foram propostos nos trabalhos, processos formativos organizados de forma a possibilitar discussões e reflexões sobre currículo, abordagem temática, interdisciplinaridade e 3MP. O objetivo dos processos formativos foi proporcionar, a partir da dinâmica dos 3MP, a construção/desconstrução de concepções relacionadas a elaboração de currículos.

No primeiro momento, da problematização inicial, foram problematizadas questões sobre a prática educativa dos participantes. Já no segundo momento Organização do Conhecimento, lidos, refletidos e discutidos textos, artigos e capítulos de livros com intuito de ampliar os conhecimentos sobre o tema. Além disso, nesse momento foram elaboradas entrevistas e questionários que foram aplicados na comunidade escolar, com pais, comunidade em geral, secretarias, órgãos públicos, dentre outros, com objetivo de investigar a realidade e a partir disso chegar aos temas geradores. $\mathrm{Na}$ 
Aplicação do Conhecimento, terceiro momento do processo vivenciado, foram realizados os planejamentos com base nos 3MP interdisciplinares e implementados em sala de aula

A construção dos questionários para o ER, foi organizada partir de quatro questões, com base no Caderno de Formação 01 (SÃO PAULO, 1990). Estas questões tiveram como objetivo facilitar a percepção de aspectos significativos nas comunidades. São elas,

\footnotetext{
- O quê? - em relação à comunidade escolar: Interesses, expectativas, relações com a comunidade, aspectos organizacionais, aspectos pedagógicos, lideranças, valores/religião, cultura/arte - relação com a comunidade local, urbanização, interesses, expectativas, relações com a escola, visão que a comunidade tem da escola quanto a aspectos pedagógicos, físicos e recursos humanos, habitação (características), população. [...] (1990, p. 32 e 33).

- Com quem? Comunidade escolar, comunidade local, outras fontes: Administração Regional, $\mathrm{NAE}$, museus, bibliotecas, núcleos regionais de planejamento, IBGE, movimentos sociais, etc. (1990, p.34 e 35).

- Como? Problematizando através de: entrevistas, questionários, conversas informais, documentos, vídeos, fotografias, etc. (1990, p. 35)

- Quem? A escola realiza este estudo preliminar com a assessoria do NAE [1] (1990, p. 35).
}

O objetivo deste momento é de relatar como emergiu o tema gerador. Para que isso fosse possível, primeiramente, procurou-se fazer uma descrição e caracterização da realidade onde a escola estava inserida, na medida em que, com o estudo dessa realidade, se pudesse obter uma temática significativa para orientar a construção de um projeto de ensino/aprendizagem via Abordagem Temática.

Para obter respostas às questões referidas, fez-se necessária a investigação a partir de entrevistas e questionários com pessoas da comunidade, responsáveis por órgãos públicos, pesquisas em jornais locais, postos de saúde, da brigada militar e comerciantes locais. Realizou-se também uma análise documental do Projeto Pedagógico das escolas no intuito de reconhecer os objetivos e as concepções das mesmas sobre o trabalho educativo. Além disso, foram realizadas conversas e entrevistas semiestruturadas (TRIVIÑOS, 1987) com educandos, educadores, pais, funcionários da escola e equipe diretiva e também foram utilizados diários da prática pedagógica das docentes e diários da pesquisadora, adaptados de Porlán e Martín (1997).

As entrevistas semiestruturadas tiveram como objetivo obter indícios, relevâncias, valores, percepções que pudessem proporcionar uma melhor compreensão da temática no contexto estudado. Identificaram-se, com essas entrevistas, contradições sociais, ou melhor, situações significativas para as comunidades em questão. Ferramentas adicionais como notas de campo e conversas informais também enriqueceram a análise deste corpus.

Dentre os indicadores que orientaram a análise e discussão dos dados, com vistas ao levantamento das situações significativas e chegada ao tema gerador estão: a inter-relação dos dados coletados com foco nas situações que representam o cotidiano da comunidade pesquisada, a consideração da frequência com que os dados apareceram e a consideração da não frequência 
quando indicador de contradições (SÃO PAULO, 1990; TORRES; O'CADIZ; WONG, 2002; MUENCHEN, 2010).

Neste sentido, os resultados que emergiram dos instrumentos utilizados na coleta de dados dos trabalhos apresentados neste artigo e do processo da análise textual discursiva foram: o tema gerador "Infraestrutura" no trabalho desenvolvido por Araújo (2015), no trabalho de Centa (2015) o tema "Arroio Cadena: Cartão Postal de Santa Maria?" e no trabalho de Paniz (2015) os temas geradores foram: "O problema do lixo no município de São Vicente do Sul tem solução?"; "Drogas: situação problema em São Vicente do Sul?”;"Drogas e a relação com a violência em Cacequi" e "O Lixo no município de São Francisco de Assis: causas e consequências".

A seguir, apresentam-se os resultados encontrados em cada um dos estudos, ou seja, os processos que culminaram na chegada aos temas geradores e suas devidas considerações.

\section{RESULTADOS E DISCUSSÃO}

Através dos trabalhos desenvolvidos nas seis escolas, apresenta-se a seguir os temas geradores evidenciados a partir do ER, bem como as potencialidades e dificuldades encontradas no processo.

\section{Tema Gerador: “Arroio Cadena: Cartão Postal de Santa Maria?": envolve a análise do dossiê construído a partir do ER.}

O contexto no qual a pesquisa foi inserida envolveu a Escola Estadual de Ensino Médio Dom Antônio Reis, foi fundada em 1961 e que tem uma população estudantil de 564 alunos. Está localizada na região norte do município de Santa Maria, no Estado do Rio Grande do Sul (RS).

O material coletado foi organizado e registrado na forma de um dossiê. Durante o processo de análise das informações obtidas no ER, problematizaram-se as possíveis situações significativas da comunidade com o intuito de sintetizá-las.

A análise documental do Projeto Pedagógico (PP) da escola permitiu uma primeira caracterização da realidade dos estudantes:

Número elevado de repetência ocasionado pelo excesso de faltas, falta de aprendizagem como interpretar textos, expressar-se com clareza; (PROJETO PEDAGÓGICO, 2007, p. 8) 
Alguns itens do PP mostram que a "transmissão" do conhecimento por parte da equipe docente não torna os conteúdos significativos para os educandos, o que, dentre outros fatores, muitas vezes, ocasiona a evasão. Sendo assim, concorda-se com Muenchen (2006), que, para isso, ocorrer torna-se necessário vincular o "mundo da escola" com o "mundo de vida".

$\mathrm{Na}$ entrevista com os educandos, a maioria dos entrevistados relatou problema da violência, querem mais policiais nas ruas. Existe tráfico de drogas e reclamam que o posto de saúde recebe poucos recursos. Também reclamam do descaso com o Arroio Cadena, como apontam as seguintes manifestações: "[...] O abandono com o rio Cadena [...]" (Educando 1). "[...] No verão, o cheiro e os mosquitos que vêm do Cadena são insuportáveis [...]" (Educando 2).

É importante ressaltar, porém, que o ER não se limita à simples coleta de dados, mas deve, acima de tudo, perceber como o educando sente sua própria realidade, superando a simples constatação dos fatos.

Para Freire (2013), a investigação e o desvelamento da realidade demandam a participação de quem dela faz parte e de suas interpretações em relação aos que vivem:

É preciso que nos convençamos de que as aspirações, os motivos, as finalidades que se encontram implicados na temática significativa são aspirações, finalidades, motivos humanos [...] Captá-los e entendê-los é entender os homens que os encarnam e a realidade a eles referida. Mas, precisamente porque não é possível entendê-los fora dos homens, é preciso que estes também os entendam (FREIRE, 2013, p. 138).

$\mathrm{Na}$ entrevista com a comunidade local, as principais reclamações da comunidade foram: inundação durante as chuvas, falta de segurança, drogas, alagamento nas ruas, Cadena abandonado, como mostram as manifestações a seguir:

\section{[...] Não há escoamento suficiente nos dias de chuva (Comerciante 1) \\ [...] O Cadena está abandonado (Morador 1). \\ [...] Os próprios moradores do bairro e que vivem no lado do Cadena jogam lixo lá (Morador 2).}

O Cadena é um grande problema para essas pessoas, pois relatam que, em vários trechos, onde se encontra o Arroio existe muito lixo, cheiro muito forte, moscas e ratos, e o comodismo com essa situação, mostra uma grande contradição com esse problema.

Durante as entrevistas com os educadores, pais, educandos e comunidade local, compreendeu-se que a violência, o tráfico de drogas e o descaso com o Arroio Cadena foram as falas mais frequentes.

Portanto, a partir de cada fala, foi possível selecionar temáticas concretas que possibilitaram o resgate histórico e dialético dos conflitos e problemas vivenciados pela comunidade. Com o 
levantamento dos dados da realidade local, realizou-se o processo de categorização e discussões sobre as principais contradições, sendo que o tema de maior relevância foi: "Arroio Cadena: Cartão postal de Santa Maria?".

Destaca-se que, no decorrer do processo formativo, os educadores elaboraram um instrumento e verificaram a relevância do tema junto às turmas de educandos. Como resultados desse processo, com a utilização do questionário, pode-se perceber um interesse por parte dos educandos quando thes é proposto se seria relevante estudar um tema como o Arroio Cadena:

\section{[...] Sim, porque poderíamos ajudar de alguma maneira (Educando 1).}

[...] Sim, porque ele é o mais importante curso d'água da cidade (Educando 2).

\section{[...] Sim, por causa da sua poluição (Educando 3)}

Essas manifestações mostram certo descontentamento com o real estado que se encontra o Arroio Cadena e ainda enfatizam que a solução para a poluição do Cadena está no próprio bairro, mostrando a visão acrítica que se encontra esses educandos. Posteriormente, foi questionado se os estudantes achavam o Cadena importante. A seguir, apresentam-se manifestações a essa pergunta:

\section{[...] Não, porque tem muita sujeira, lixo, cheira mal (Educando 12). \\ [...] Não, por ser muito poluído (Educando 15). \\ [...] Não, porque é um lixão (Educando 17).}

De imediato, essas falas demonstram algumas contradições, primeiramente, porque os educandos mostram um descontentamento com a atual situação, porém, percebe-se uma preocupação, faz parte da vida deles. Nas últimas falas, foi possível perceber que o Cadena, para eles, não é importante, pois, só traz aborrecimentos: "[...] se ele fosse cuidado seria importante, mas como ele está, só traz problemas [...]” (Educando 4).

Dessa forma, o mundo da vida, os problemas e as contradições manifestos nas diversas falas passam a ser o ponto de partida para a construção de uma programação curricular crítica que busca a compreensão da realidade. Após o ER, as próximas etapas foram realizadas no segundo e terceiro momentos pedagógicos. 


\section{A Imersão do ER para a obtenção do Tema Gerador "Infraestrutura"}

Em relação a este trabalho, a pesquisa desenvolveu-se na escola pública da rede estadual da cidade de Santa Maria/RS Instituto Estadual Luiz Guilherme do Prado Veppo - a escolha por esta escola se deu, em função da mesma estar inserida em uma região da cidade de Santa Maria que enfrenta muitos problemas sociais e estruturais. A escolha também ocorreu, pelo fato de que a escola apresenta uma organização curricular diferenciada de trabalho que encontra-se em sintonia com alguns dos objetivos da dinâmica dos 3MP, tais como o trabalho coletivo e interdisciplinar. Isso é possível de se verificar, em um trecho do Projeto Pedagógico da escola:

Dá-se prioridade para um trabalho interdisciplinar, isto é, o trabalho realizado em sala de aula será desenvolvido de forma globalizada agrupando-se disciplinas afins que compõem cada área. Cada disciplina terá seu professor específico que trabalharão em conjunto em sala de aula. Cada área terá dois blocos/semanal em cada série. Portanto, a carga horária é distribuída igualmente em todas as áreas de estudo (PP, 2011, p. 11).

Buscou-se, com o desenvolvimento desta pesquisa, possibilitar que os docentes da escola citada acima, percebessem que o seu papel docente extrapolava os limites da sala de aula. Seu papel, concentrou-se em ser sujeito ativo no processo de construção curricular da escola com base na dinâmica dos Três Momentos Pedagógicos (3MP), possibilitando aos educandos um ensino pautado pelo diálogo e problematização, propiciando a participação destes no processo de ensinoaprendizagem.

Neste sentido, Araújo (2015) destaca a necessidade do contato das docentes com a realidade dos educandos, sendo que as participantes do curso participaram integralmente do mergulho na comunidade, realizando entrevistas e conversas informais com os moradores, comunidade escolar, comerciantes, alunos e posto de saúde. Constatou-se isso nas entrevistas realizadas com as docentes, sendo possível de se verificar a seguir:

Eu acho que embora eu não me achasse tão longe deles, eu acho que essa maior aproximação foi que me levou a discutir situações da vida deles, que se eu não tivesse ido à comunidade eu não saberia né, como essa fragilidade social que eles têm. E aí, eu acho que forço uma aproximação maior, e essa aproximação maior tornou eles mais receptivos [...] (Prof. 1).

Para a realização do ER, o coletivo de docentes confeccionaram materiais para a construção do dossiê, sendo realizadas entrevistas com a comunidade local de onde os educandos emergiam (comerciantes, pais dos educandos, moradores do bairro), com o posto de saúde da comunidade, com a equipe diretiva da escola, professores, funcionários da escola, estudantes e foram realizadas conversas informais, análise de fotografias e documentos. 
Após o mergulho na comunidade, análise de documentos, fotos, conversas informais, visita ao posto de saúde, o coletivo de professores categorizou as informações obtidas e, as situações significativas que resultaram deste processo foram drogas, segurança, transporte, saúde, rede de esgoto e lixo. Verifica-se a seguir, manifestações quanto a esses problemas que são vivenciados na comunidade em que o trabalho foi realizado:

[...] um grande problema é os alunos saírem de casa nos dias de chuva, devido ao alagamento das ruas. (Professor 1).

O saneamento, esgoto a céu aberto. Deveria ter tubulação de esgoto. E quando chove alaga as ruas porque tem muito lixo acumulado (Morador 3).

Acho que somos esquecidos pela prefeitura, porque as ruas do nosso bairro estão horríveis, a saúde poderia mudar, tem poucos médicos e melhorar o transporte também (Aluno 4).

Teria que ter mais ônibus, principalmente de manhã e de tardezinha, é pouco horário. Sem contar que a passagem está bem cara e os ônibus estão precários (Aluno 1).

São muitos os problemas enfrentados no bairro, mas acredito que o saneamento básico, segurança na faixa na frente da escola e drogas são os principais (Equipe Diretiva).

Após a categorização do material coletado e dos subtemas que emergiram deste processo, o tema emergente foi Infraestrutura (ARAÚJO, 2015).

Com o desenvolvimento do tema Infraestrutura, procurou-se discutir com os educandos os problemas que a comunidade apresentava e, a partir das discussões e das atividades realizadas, possibilitar que estes sujeitos tornem-se capazes de intervir e modificar a sociedade que se encontram imersos.

Segundo Araújo (2015), o tema Infraestrutura por emergir da Investigação Temática, o qual apresenta os problemas da comunidade dos educandos, é caracterizado como sendo um tema gerador. O tema, de fato, é caracterizado como gerador por apresentar manifestações locais da realidade concreta dos educandos, propiciando, com isso, um estímulo ao que Freire (1992) denomina de curiosidade epistemológica, dimensão central no ato de aprender, fortalecendo o processo de ensino/aprendizagem e estimulando a cultura de participação.

Destaca-se ainda, o envolvimento e a participação dos educandos com o tema emergido do processo do ER, verificando-se assim, que os problemas emergentes da comunidade em que eles encontram-se inseridos proporcionaram um interesse e uma participação maior nas discussões acerca deste tema: 
A interação dos alunos junto com os professores, em tudo assim. Cada um deu a sua opinião, porque esse tema que foi trabalhado todo mundo conhece um pouco, pelo bairro, ou que já ouviu falar por aí, em outros lugares de Santa Maria. Então, eu acho que foi muito interessante (Aluno 8).

É um tema do dia-a-dia, não é uma matéria nova né, que poucos sabem, é uma coisa que a pessoa usa, depende daquilo né. Ficava todo mundo dando opinião e todo mundo tem uma opinião sobre isso também (Aluno 10).

Após a determinação do tema "Infraestrutura", assim como no projeto anterior, encaminharamse os outros dois momentos, ou seja, a OC e a AC. Destaca-se que, após a obtenção do tema que emergiu dos problemas da comunidade local e escolar e da necessidade de um olhar sobre este tema, foram direcionados os planejamentos das aulas e a implementação das mesmas, com base na dinâmica dos 3MP.

\section{A obtenção dos Temas Geradores a partir da interação entre formação inicial e continuada}

Um dos trabalhos desenvolvidos e apresentados no presente artigo, teve como participantes bolsistas e supervisores do Programa de Bolsa de Iniciação à Docência (PIBID) do Instituto Federal Farroupilha-campus São Vicente do Sul das licenciaturas em Ciências Biológicas e Licenciatura em Química, totalizando 30 sujeitos que desenvolvem atividades em quatro escolas da $8^{\circ}$ Coordenadoria de Educação e são parceiras do PIBID.

A busca pelos temas geradores se deu a partir de um processo formativo implementado com bolsistas e supervisores do PIBID que aconteceu de março até dezembro de 2014. Durante o processo formativo foram discutidos textos sobre tema gerador, currículo, três momentos pedagógicos e interdisciplinaridade.

Na continuidade, os participantes foram organizados por escola de maneira que em cada grupo tivessem bolsistas e supervisores da Biologia e da Química. Posteriormente, cada grupo elaborou questionários para a realização do ER. Além disso, foram realizadas investigações em jornais, blogs, secretarias da saúde e meio ambiente, dentre outros órgãos públicos. Foram entrevistadas pessoas da comunidade, pais, alunos e professores no intuito de reconhecer quais os problemas vivenciados em cada município.

A partir da investigação chegou-se aos temas geradores "Drogas: situação problema em São Vicente do Sul?" "O problema do lixo no município de São Vicente do Sul tem solução?"; "Drogas e a relação com a violência em Cacequi" e "O Lixo no município de São Francisco de Assis: causas e consequências".

Em relação ao tema Drogas: situação problema em São Vicente do Sul? evidenciado por uma das escolas parceiras, destaca-se as falas da comunidade, pais e alunos que elegeram a questão das drogas como uma situação problema no município, como é possível visualizar a seguir. 
O crescimento da marginalidade e falta de segurança. Muita droga, muito uso de drogas e a polícia não consegue controlar (SUJEITO A).

Precisa medidas mais rígidas, pois as drogas estão tomando conta (SUJEITO $B)$.

A visão da comunidade em geral sobre o tema drogas é a de que a expansão do uso na cidade está relacionada à falta de medidas repreensivas. Os entrevistados não destacaram a escola como possível instituição que pode discutir e proporcionar reflexão e conhecimento sobre o assunto, como se observa na fala a seguir, evidenciando desta forma, a necessidade de discussão sobre o tema na escola.

Não, só a prefeitura pode fazer isso (SUJEITO C)

Em relação ao tema: O problema do lixo no município de São Vicente do Sul tem solução? destaca-se que inicialmente o grupo tinha expectativa de que o tema seria relacionado a drogas também, já que ambas as escolas, estão localizadas no mesmo município. No entanto, os alunos são oriundos em sua maioria, das periferias da cidade e do interior, diferente da maioria dos alunos da outra escola que são do centro. Existe uma fala entre os moradores, e até mesmo, entre os professores afirmando que a "São Vicente recebe mais a elite da cidade, enquanto o Borges o povo mais carente" (PANIZ, 2016).

A obtenção do tema, nesta escola ficou bem evidente, pois o problema do lixo destacou-se nas entrevistas com sujeitos da comunidade escolar e da comunidade em geral.

Existe muito lixo jogado e esgoto (SUJEITO O).

As pessoas da cidade vão levar seus lixo e jogam nas estradas do interior (SUJEITO A).

A gente as vezes não sabe o que fazer com o lixo aqui no interior. Tem coisas que não pode ser misturada com lixo normal, tipo vasilhas de venenos (SUJEITO F).

Em relação à terceira escola, havia uma hipótese inicial, pensada pelo grupo, de que o tema escolhido seria o problema do roubo na cidade, pois existem vários relatos e casos de furto na comunidade, que está localizada nas beiras do trilho de trem, onde muitas vezes, os vagões são arrombados e assaltados, mesmo com o trem em andamento (PANIZ, 2016). No entanto, o tema que 
emergiu a partir das pesquisas foi o problema das drogas e a relação com a violência como pode ser visualizado abaixo.

As drogas são um problema, elas estragam a vida das pessoas. Os que bebem por exemplo, podem sair por ai batendo nas pessoas e batendo carro (SUJEITO A).

Tem drogas que afetam o cérebro e deixam as pessoas loucas, violentas (SUJEITO B).

Tem uns que usam drogas e batem na mulher e nos filhos (SUJEITO C).

Por fim, o tema gerador evidenciado na quarta escola foi O Lixo no município de São Francisco de Assis: causas e consequências, que, a partir das pesquisas com a comunidade escolar e com a comunidade em geral, verificou-se que é um tema atual no município (PANIZ, 2016).

Nas conversas com a comunidade foram evidentes as concepções de que a falta de educação do próprio povo é um problema no município.

Falta de consciência da população para cuidar do meio ambiente (SUJEITO A).

A prefeitura devia ajudar, pois tem muito povo carente que não sabe a importância do meio ambiente (SUJEITO B).

Até tem campanhas sobre o lixo, mas não adianta, o povo é relaxado (SUJEITO C).

A interação entre escola e comunidade se mostrou efetiva em relação ao diálogo e a troca de experiências e ideias. Por isso, o que defendemos é que a escola seja um espaço de valorização dos saberes e das ideias dos sujeitos que estão ligados direta ou indiretamente à ela. Assim, é preciso que a escola comece a indagar o que ensinar e porque ensinar determinado conteúdo? Que valorize a participação dos sujeitos e que haja uma aproximação entre o mundo da escola e o mundo da vida. Essa valorização da comunidade na elaboração do currículo proporcionou aos licenciandos outra visão da escola, dos professores e de si próprios enquanto futuros docentes. Foi possível reconhecer o papel ativo dos sujeitos e dos professores enquanto pensadores de currículo e não mais como meros reprodutores de lista de conteúdos.

Após o ER, as próximas etapas foram realizadas a partir do segundo e terceiro momentos pedagógicos. 


\section{CONSIDERAÇÕES FINAIS}

$\mathrm{Na}$ primeira fase do desenvolvimento curricular, foi realizado o reconhecimento local das comunidades em que as escolas estão inseridas. Ao investigar quais as situações e as contradições sociais vivenciadas pelos envolvidos, chegou-se à percepção individual e coletiva dos problemas que a comunidade enfrenta, sendo que, dessas situações significativas, emergiu os temas geradores.

A perspectiva da ATF aponta para que efetivas transformações na educação ocorram necessita-se de um olhar com cuidado ao currículo. Não adianta o currículo ser visto como uma lista de conteúdos a serem vencidos, é preciso considerar os problemas locais para seleção dos conhecimentos e, com isso, ter a participação dos educadores na construção deste.

Ainda, o currículo nesta perspectiva educacional é pautado no trabalho com temas geradores, que remete a interdisciplinaridade, dialogicidade, conscientização, problematização, abarcando, assim, as contradições envolvidas nas relações sociais, econômicas e culturais do local, ou seja, do mundo do educando. Podendo potencializar ao educando a libertação da sua situação de oprimido e lutar para a transformação da sua realidade.

Não se pode, então, desvincular o currículo da formação docente. Assim, a partir dos processos formativos vivenciados nas seis escolas, foi possível reconhecer a importância da reestruturação curricular no sentido da valorização da participação dos sujeitos em sua elaboração. 0 ER considera as vivências, problemas e situações vivenciadas pela comunidade, aproximando-a da escola.

Nesse sentido, a escola necessita repensar seu papel, não restringindo-se a transmissão de conhecimentos, mas sim sendo um espaço de discussão de ideias, de troca de conhecimentos e experiências e de convívio produtivo, pois esta não é um conjunto de aulas, é muito mais que isso, deve ser um projeto da comunidade compartilhado que se desenvolve em um contexto, por meio da ação conjunta de todos os sujeitos envolvidos.

Cabe destacar que os trabalhos implementados a partir das vivências no grupo GEPECiD, que vem sendo implementado processos formativos em escolas públicas, possui esse intuito de proporcionar a reflexão e a problematização da realidade vivenciada pelos sujeitos.

Destaca-se ainda que no decorrer dos processos formativos muitas situações problema foram vivenciadas, pois a maioria dos professores vêm de uma cultura escolar na qual apenas trasmitem o que está no livro didático e nos manuais de processos seletivos. Essa mudança de postura, incialmente foi marcada pela visão de "não saber" dos professores que se sentiram inseguros durante o processo. No entanto, a partir do momento que reconheceram a importância em ouvir a comunidade e em quanto mesmo trabalhando na escola não conheciam a realidade de seus próprios alunos, iniciou-se um processo de reconstrução e reflexão da própria prática que resultou em um trabalho participativo, dialógico e problematizador. 


\section{REFERÊNCIAS}

1. ARAÚJO, Lais B. Os três Momentos pedagógicos como estruturantes de Currículo. 2015. 150f. Dissertação (Mestrado em Educação em Ciências) - UFSM, Santa Maria.

2. AULER, Neiva; AULER, Décio. (Org.). Concepção e Execução de Currículo no Processo Formativo de Licenciandos do Pibid. 1ed. ed. Curitiba: CRV, 2015.

3. AULER, Décio. Enfoque Ciências-Tecnologia-Sociedade: Pressupostos para o Contexto Brasileiro. Ciência \& Ensino, vol. 1, número especial. 2007.

4. BRASIL. Diretrizes Curriculares Nacionais Gerais da Educação Básica. Brasília: 2013

5. BRASIL. Pacto Nacional pelo fortalecimento do Ensino Médio. Secretaria de Educação Básica, Ministério da Educação Diretoria de Apoio à Gestão Educacional. Brasília: 2014.

6. DELIZOICOV, Demétrio; ANGOTTI, José; PERNAMBUCO, Marta. Ensino de Ciências: fundamentos e métodos. 4. ed. São Paulo: Cortez, 2011.

7. DELIZOICOV, Demétrio; ANGOTTI, José. Metodologia do ensino de ciências. São Paulo: Cortez. 1992.

8. DELIZOICOV, Demétrio; ANGOTTI, José. Física. São Paulo: Cortez, 1990.

9. CENTA, Fernanda; MUENCHEN, Cristiane. Em busca de um Tema Gerador a partir do Estudo da Realidade: "Arroio Cadena: Cartão Postal de Santa Maria?". In: X Encontro Nacional de Pesquisa em Educação em Ciências, 2015, Águas de Lindóia. Anais...Águas de Lindóia: ENPEC, 24-27, nov. 2015.

10. CentA, G. Fernanda. "Arroio Cadena: Cartão Postal de Santa Maria?": Possibilidades e Desafios em uma Reorientação Curricular na perspectiva da Abordagem Temática. 2015. $203 f$. Dissertação (Mestrado em Educação Matemática e Ensino de Física) - UFSM, Santa Maria.

11. FREIRE, Paulo. Política e educação. 10. ed. São Paulo: Cortez, 2001.

12. FREIRE, Paulo. Pedagogia do oprimido. 47. ed. Rio de Janeiro: Paz e Terra, 2013.

13. FREIRE, Paulo. Pedagogia da Esperança: um reencontro com a pedagogia do oprimido. 16. ed. Rio de Janeiro: Paz e Terra, 1992 
14. HALMENSCHLAGER, Karine. Abordagem de temas em Ciências da Natureza no Ensino Médio: implicações na prática e na formação docente. 2014. 373f. Tese (Doutorado em Educação Científica e Tecnológica) - UFSC, Santa Catarina.

15. MALDANER, Otávio. Situações de Estudo no Ensino Médio: nova compreensão de educação básica. In: NARDI, R. (Org). A pesquisa em Ensino de Ciências no Brasil: alguns recortes. São Paulo: Escrituras, 2007.

16. MUENCHEN, Cristiane. A Disseminação dos Três Momentos Pedagógicos: um estudo sobre as práticas docentes na região de Santa Maria/RS. 2010. 273. Tese (Doutorado em Educação Científica e Tecnológica) - UFSC, Santa Catarina.

17. MUENCHEN, C.; DELIZOICOV, D. A construção de um processo didático-pedagógico dialógico: aspectos epistemológicos. Ensaio: Pesquisa em Educação em Ciências (Online), Belo Horizonte/MG, v. 14, n. 03, set./dez. 2012, p. 199-215.

18. PANIZ, Catiane. M. Os Três Momentos Pedagógicos como Estruturantes de Currículos e a Formação de Educadores: O PIBID como Possibilidade de Articulação. (Qualificação de Doutorado), Santa Maria, PGEEC/UFSM, 2016.

19. PORLÁN, Rafael; MARTÍN, J: El diario del profesor: un recurso para la investigación en la aula. Sevilla: Díada, n. 6, 1997. (Coleção Investigación y Enseñanza).

20. RIO GRANDE DO SUL. Instituto Estadual Luiz Guilherme do Prado Veppo. Projeto Político Pedagógico. Santa Maria: 2011

21. SAMPAIO, Maria Ferreira; QUADRADO, Alice; PIMENTEL, Zita. Porto. Interdisciplinaridade no município de São Paulo. Brasília: INEP, 1994.

22. SÃO PAULO. Cadernos de Formação 01, 02 e 03. Série Ação Pedagógica na escola pela via da interdisciplinaridade. Secretaria Municipal de Educação. São Paulo: DOT/SME-SP, 1990.

23. TORRES, Carlos Alberto; O'CADIZ, Maria; WONG, Pia. Educação e democracia: a práxis de Paulo Freire em São Paulo. São Paulo: Cortez/Instituto Paulo Freire, 2002.

24. TRIVIÑOS, Augusto. N. A pesquisa qualitativa em educação. São Paulo: Atlas, 1987. 


\section{Catiane Mazocco Paniz:}

Professora do Instituto Federal Farroupilha-campus São Vicente do Sul, mestre em Educação pela UFSM.

\section{Fernanda Gall Centa:}

Bacharel/Licenciada em Física pela UFSM, mestre em Ensino de Física pela UFSM.

\section{Laís Baldissarelli Araújo:}

Professora do Instituto Estadual Monsenhor Scalabrini e Colégio Estadual de llópolis, mestre em Educação em Ciências pela UFSM.

\section{Cristiane Muenchen:}

Professora da UFSM, doutora em Educação Científica e Tecnológica pela UFSC.

\section{Como citar este documento:}

PANIZ, Catiane Mazocco et al. OS TRÊS MOMENTOS PEDAGÓGICOS COMO ESTRUTURANTES DE CURRÍCULOS: O ESTUDO DA REALIDADE E OS TEMAS GERADORES NA EDUCAÇÃO EM CIÊNCIAS. Reflexão e Ação, Santa Cruz do Sul, v. 26, n. 2, ago. 2018. ISSN 1982-9949. Disponível em: <https://online.unisc.br/seer/index.php/reflex/article/view/8945>. Acesso em: __. doi: http://dx.doi.org/10.17058/rea.v26i2.8945. 